NBER WORKING PAPER SERIES

\title{
GLOBAL INEQUALITY WHEN UNEQUAL COUNTRIES \\ CREATE UNEQUAL PEOPLE
}

\author{
Martin Ravallion \\ Working Paper 24177 \\ http://www.nber.org/papers/w24177 \\ NATIONAL BUREAU OF ECONOMIC RESEARCH \\ 1050 Massachusetts Avenue \\ Cambridge, MA 02138 \\ December 2017
}

The comments of Dan Cao, Denis Cogneau, Ed Diener, Richard Easterlin, Emmanuel Flachaire, Ravi Kanbur, Christoph Lakner, Branko Milanovic, John Rust and Dominique van de Walle are gratefully acknowledged. The views expressed herein are those of the author and do not necessarily reflect the views of the National Bureau of Economic Research.

NBER working papers are circulated for discussion and comment purposes. They have not been peer-reviewed or been subject to the review by the NBER Board of Directors that accompanies official NBER publications.

(C) 2017 by Martin Ravallion. All rights reserved. Short sections of text, not to exceed two paragraphs, may be quoted without explicit permission provided that full credit, including () notice, is given to the source. 
Global Inequality when Unequal Countries Create Unequal People

Martin Ravallion

NBER Working Paper No. 24177

December 2017

JEL No. D3,D6,I3,O15

\begin{abstract}
$\underline{\text { ABSTRACT }}$
Current global inequality measures assume that national-mean income does not matter to economic welfare at given household income, as measured in surveys. The paper questions that assumption on theoretical and empirical grounds and finds that prominent stylized facts about global inequality are not robust. At one extreme, theories of relative deprivation yield a nationalistic measure whereby global inequality is average within-country inequality, which is rising. Other theories and evidence point instead to an intrinsic value to living in a richer country. Then parameter values consistent with subjective wellbeing imply far higher global inequality than prevailing measures, though falling since 1990.
\end{abstract}

\author{
Martin Ravallion \\ Department of Economics \\ Georgetown University \\ ICC 580 \\ Washington, DC 20057 \\ and NBER \\ mr1185@georgetown.edu
}




\section{Introduction}

The prevailing approach to measuring global inequality pools all household incomes in the world and measures inequality in this global distribution the same way one measures inequality within one country. This has been dubbed the "cosmopolitan” approach in that everyone in the world is treated the same way. ${ }^{2}$ Three stylized facts have emerged from the literature following this approach: ${ }^{3}$ (i) the bulk of global inequality (two-thirds to three-quarters) is between countries rather than within them; (ii) inequality between countries has been falling since around 1990, while average inequality within countries has been rising; and (iii) on balance, global inequality has been falling.

We have seen diverse reactions to this pattern. Some observers have argued that falling global inequality diminishes the need for further redistributive effort, including in addressing high and rising inequality within countries. ${ }^{4}$ Another view is that rising inequality in rich countries is an unwelcome consequence of the falling inequality between-countries, as jobs appear to move to the developing countries that are far poorer but are enjoying higher growth rates during the current period of globalization and convergence. ${ }^{5}$

However, there appears to be a salience to nationality that is missing from the cosmopolitan approach to measuring global inequality, at least as it is commonly implemented empirically. ${ }^{6}$ That salience stems in large part from the fact that many of the arguments made against high inequality relate to residents of a given country rather than the world as a whole. ${ }^{7}$ An example is the commonly-heard concern about economically-powerful elites dominating political and judicial decision making at national and local levels. Similarly, the relevant domain for personal evaluations of status and self-respect in unequal societies often appears to be national rather than global. The standard cosmopolitan approach to global inequality can be in tension with the idea that ideals of "equity” or "justice” are confined to a set of "moral

\footnotetext{
2 This is the term used by Brandolini and Carta (2016), in keeping with the usage in Caney (2005) and Nagel (2005).

${ }^{3}$ Further discussion of these stylized facts can be found in Bourguignon (2015), Lakner and Milanovic (2016), Milanovic (2015, 2016) and Ravallion (2017a). Note that stylized fact (ii) represents a marked reversal in the longrun pattern back to the early $19^{\text {th }}$ century, as documented by Bourguignon and Morrisson (2002).

${ }^{4}$ For example, Cowen (2014) uses declining inequality between countries as an argument against intra-national redistribution. See the comments by Bhattacharya (2014) and the Economist (2014).

${ }^{5}$ These views are discussed further in Bourguignon (2015), Milanovic (2016) and Rodrik (2017).

${ }^{6}$ Kanbur (2006) makes a similar point about "between-group” inequalities such as based on gender or ethnicity.

${ }^{7}$ This applies to most of the arguments for “non-intrinsic egalitarianism” made by O’Neill (2008).
} 
comparators," being people who are bound in some personal relationship, as in the approach found in Walster et al. (1978). It has often been argued that for most people such relationships are quite localized — rarely extending beyond the borders of the country of residence.

One possible response to these concerns is to reject cosmopolitanism by down-weighting foreigners. In the limit, "global inequality” is then nothing more than the average inequality within countries. That can be thought of as an implication of political nationalism - that distributional concerns and redistributive efforts are confined to fellow nationals. ${ }^{8}$ For example, in keeping with his contractarian approach to questions of social justice, Rawls (1999) argues that people living in rich countries only have a moral obligation to help those in poor countries when (and only when) the latter are not well governed, such that the people live in "burdened societies."9 Such arguments motivate abandoning cosmopolitanism in favor of a more nationalistic approach for measuring global inequality. For example, this is the approach taken by Brandolini and Carta (2016) who postulate a social welfare function that treats people equally within the country of residence but puts lower weight on foreigners.

Yet, to many observers, including this author, a cosmopolitan approach to measuring global inequality is compelling. Yes, nations exist and their governments address (in various ways) inequality within their borders (and beyond them, such as through development assistance). While the institutional fact of nation states and the limitations of global institutions may entail severe constraints on what global redistribution can be achieved in practice, these facts cannot dull the moral case for a cosmopolitan perspective in thinking about "global inequality" - a perspective that values all people of the world equally, no matter where they may happen to have been born. This echoes the arguments of Nagel (2005), Singer (2010) and others that national borders are not morally relevant to the case for helping disadvantaged fellow human beings. That implies an unconditional commitment to the cosmopolitan view in measuring global inequality. Can such a commitment be reconciled with a concern about national identity?

This paper offers an approach to measuring global inequality that maintains the essence of cosmopolitanism but recognizes that one's view of global inequality, and the implications one draws for assessing global economic developments and policies, depends on how one values

\footnotetext{
8 The term "nationalistic" can be used in different ways. Here it refers solely to how one thinks about global inequality. In that context, the present usage is broadly consistent with others, such as Beck (2006).

${ }^{9}$ For a critical assessment of this and other aspects of Rawls (1999) see Buchanan (2000).
} 
national income in assessing individual economic welfare. The literature on global inequality has long recognized the existence of a "citizenship premium" (Milanovic, 2016, p.131) from living in a rich country, but has implicitly assumed that this premium is fully reflected in household income or consumption expenditure per person as measured in a household survey (normalized to constant prices). That seems unlikely. Indeed, there are many reasons why national income can matter to individual welfare at given own-income. One possibility that has been considered in the literature is relative deprivation (Duesenberry, 1949; Runciman, 1966). Following this approach, Ravallion and Chen (2011) and Milanovic and Roemer (2016) assume that individual economic welfare depends on both own-income and relative income, defined as own-income relative to the mean for the country of residence. ${ }^{10}$ Then higher mean income has a negative direct welfare effect. Intuitively, this suggests less inequality than implied by standard measures. If the effect of relative deprivation is large enough then we end up with a strongly nationalistic perspective on global inequality, which depends solely on the within-country component in current measures.

However, there can also be positive external effects of living in a wealthier country. The contextual factors are transmitted via better institutions, better public services, greater security and greater opportunities for economic gain, leisure and social protection, all of which can be expected to depend positively on mean income in the country of residence. And these positive effects could well dominate the negative effects associated with relative deprivation. To the extent that those living in richer countries are intrinsically better off there is even greater inequality in the world than suggested by current measures using survey-based own-incomes. The inequality between countries becomes an extra source of inequality between people. In short, unequal countries create (horizontally) unequal people at the same observed income. Surprisingly, this possibility has been ignored in the literature on measuring global inequality.

The paper studies how sensitive the findings in the literature on global inequality are to allowing national income to matter intrinsically to individual economic welfare. The proposed alternative measure is not simply a re-weighting of the "between" and "within" components of

\footnotetext{
${ }^{10}$ In the context of measuring relative poverty, Ravallion and Chen (2011) consider a welfare function of the form $w(y, y / m)$ where $y$ is own-income, $m$ is the country mean and the function $w$ is strictly increasing in both arguments. Milanovic and Roemer (2016) consider a welfare function of the form $y^{1-\lambda}(y / m)^{\lambda}$ where $0 \leq \lambda \leq 1$. Neither formulation allows a positive external welfare effect of living in a country with a higher mean income.
} 
inequality, but requires a new measure, consistent with the underlying valuations of differences in national income. Both positive and negative effects are allowed empirically. At one extreme, a purely nationalist measure emerges. Another special case is the prevailing implementation of the cosmopolitan approach. However, the paper also studies the implications of the neglected case in the literature, whereby higher national income has a positive value at given own income.

The paper finds that stylized fact (i) and (iii) are not robust to allowing national income to matter intrinsically over the range of parameter values considered. One can obtain rising or falling global inequality, and the "between-within” decomposition changes substantially. Even a seemingly modest weight can generate anything from a large reduction in measured inequality to a large increase. And the changes are larger than one sees over time, or that one obtains with adjustments for underreporting of incomes by the rich. While further research is called for, the paper argues that there is a stronger case for the view that higher national income has a positive intrinsic value, implying higher global inequality than is thought, though falling since 1990. Indeed, the trend decline in global inequality since 1990 is robust to all except a strongly nationalistic view.

The following section points to reasons why national income matters intrinsically, implying that a new approach to measuring global inequality is called for. Section 3 outlines the paper’s approach. Section 4 presents the results on global inequality measures. Section 5 concludes.

\section{Arguments and evidence as to why national income matters}

Standard measures of global inequality are based on household disposable income or consumption expenditure derived from a household survey. The household aggregate for income or consumption is then normalized for differences in the prices faced and household size (and possibly composition). The resulting measure is taken to be a sufficient statistic for individual real income. Yet there are some well recognized limitations of such data. The constraint of relying on respondent recall in surveys entails that income or consumption is typically only measured over a relatively short recall period. Nor is access to non-market goods, including some public services, typically accounted for. 
Why national income matters intrinsically: In the standard approach to measuring global inequality, mean national income only matters in so far as it influences individual own income, as measured in surveys. ${ }^{11}$ It is plausible that the country of residence matters to personal income. ${ }^{12}$ This is the instrumental case for why national income matters. However, there are also reasons to postulate an independent intrinsic effect of national income. Four main reasons can be identified, two of which imply a negative effect while it is positive for the other two.

First, the "relative income hypothesis" of Duesenberry (1949) postulates that individual welfare depends on how the individual is doing relative to a set of comparators. ${ }^{13}$ In this context, a higher mean in the country of residence is taken to give disutility at given own-income through perceptions of relative deprivation. ${ }^{14}$ Easterlin (1974) argues that the only way income matters to subjective welfare is through its relative value, i.e., relative to national income. ${ }^{15}$ This is how he explains the seemingly weak response of average national happiness to aggregate economic growth. (The discussion will return to the evidence on this issue.) Proponents of this approach advocate that evaluations of individual real income are purely relative, and in the context of measuring global inequality it is natural to think of the mean national income as the deflator for own income.

The discussion will return to the evidence on relative deprivation using data on subjective wellbeing, but there is an observation that can be made from another data source. The fact that the real values of national poverty lines rise with mean income can be interpreted as support for the idea of relative deprivation (Ravallion and Chen, 2011). That interpretation assumes that the national lines represent a (roughly) common level of welfare across countries, so that the observed lines can be interpreted as money metrics of that common level of welfare. This cannot be considered conclusive, however, since the reference level of welfare implicit in a national poverty line may well be an increasing function of the mean. Thus there is an identification

\footnotetext{
11 This dependence of own-income on national income is typically implicit in past approaches, but is made explicit in Milanovic (2015).

12 There is supportive evidence in the results of Clemens et al. (2008) on the determinants of labor market earnings and the results of McKenzie et al. (2010) on the income gains from migration.

${ }^{13}$ Important early contributions in sociology were made by Davis (1959) and Runciman (1966). In economics, social effects on welfare have been used to explain self-assessed welfare and aspects of behavior, including Duesenberry (1949), Easterlin (1974), Frank (1985), and Clark et al. (2008).

${ }^{14}$ Rayo and Becker (2007) show that such utility functions can emerge endogenously (interpreted as the end-point of an evolutionary process) given the difficulty in distinguishing close options and the boundedness of happiness.

${ }^{15}$ Subjective welfare (also called "subjective wellbeing”) here refers to self-assessed happiness or "satisfaction with life” based on survey questions.
} 
problem in what can be inferred from the fact that national lines rise with the mean (Ravallion and Chen, 2017).

The second reason starts with the observation that we would ideally measure real income over a longer time period than that for which current income is measured in surveys. This is well recognized in principle, but largely ignored in the practice of inequality measurement. For example, Milanovic (2016, p.131) discusses the role that country of residence plays in determining "lifetime income” through the aforementioned citizenship premium. But lifetime income is not what is measured in surveys. Current national mean income may then be a relevant indicator of expected future own-income, given that this need not be reflected well in the available income metric. What then might national mean income reveal about expected future income? In a neoclassical growth model, higher mean national income implies a higher capital stock per capita. With diminishing returns to capital and a given technology, future growth rates will then be lower in countries with a higher current mean-giving a process of economic convergence among countries with a similar long-run (steady-state) mean income. ${ }^{16}$ This argument points to a negative effect of higher national income at given (survey-based) ownincome even without perceptions of relative deprivation.

Third, it can be argued that higher mean income in the country of residence is associated with advantages that are not reflected in the prevailing implementations of the cosmopolitan approach based on household consumption or income from surveys. There are a number of sources of such direct advantage. One way this can happen is through external benefits of living in a society with a better educated population, as postulated in the Lucas (1988) model of endogenous economic growth. As is well recognized, this can readily modify the convergence property in the second argument above, which assumes similar fundamentals (including technology) and (hence) a similar long-run mean income across countries. Against this view, there is evidence of a strong negative effect of current poverty incidence on growth rates, alongside the neoclassical conditional convergence property (Ravallion, 2012). The citizenship premium of living in a country that is richer today will then entail a higher expected long-run (steady-state) level of real income. This can be interpreted as a positive real-income effect of current national mean income at given current own-income.

16 See, for example, Barro and Sala-i-Martin (1995). 
But even without such dynamic effects, or deficiencies in current income measures from surveys, the prevailing implementation of the cosmopolitan approach excludes direct gains from better provision of non-market goods and services (except those that generate direct income transfers, which are already reflected in standard income or consumption aggregates). Almost all public services are provided at the national (or more local) level, not globally. Nation states are clearly important institutions for providing local public goods, generating positive externalities for those living in well-endowed countries. Across countries and over time, public spending tends to rise with mean income-a pattern known as Wagner's Law (Musgrave, 1969; Peacock and Scott, 2000; Akitoby et al., 2006; Afonso and Alves, 2017). ${ }^{17}$ While Wagner's Law need not apply to all types of public spending, it is a plausible assumption that richer countries have better public goods and that these deliver welfare gains. (This can be thought of as another source of differences in long-run mean income in a dynamic model.) Administrative capabilities also improve, allowing better regulatory controls to allow, for example, cleaner environments in richer countries. There is no guarantee that higher average income yields such benefits; that depends crucially on domestic policy choices. However, mean income is clearly relevant, and in a positive way.

The opportunities for leisure also appear to be greater in richer countries, again generating direct welfare gains not reflected in observed incomes. Higher productivity creates such opportunities. Richer countries are clearly also better endowed with public goods that are complementary to leisure. Consistent with this further source of intrinsic value to living in richer countries, Bick et al. (2017) find that average hours of work per adult tend to be lower in countries with higher average incomes.

The fourth reason is that having better off co-residents can facilitate better insurance through both formal and informal risk-sharing arrangements. There is evidence consistent with the view that publically-provided social protection tends to be better in countries with a higher mean income (Ravallion, 2016, Chapter 10). This is also a common finding of theoretical models of informal (non-governmental) risk-sharing (Coate and Ravallion, 1993; Ligon et al., 2002; Ravallion, 2008) and the prediction has found empirical support in lab experiments (Charness

\footnotetext{
${ }^{17}$ Wagner's Law is sometimes defined as a rising share of national income devoted to government spending as income rises. Afonso and Alves (2017) provide a review of the empirical literature. Wagner's Law is generally thought to be a feature of industrialized countries, but the same pattern is found in data for developing countries, as shown by Akitoby et al. (2006).
} 
and Genicot, 2009). Positive externalities can arise via one’s current income or be an independent effect, such as through greater personal security in the presence of uninsured risks. Since it is repeated interaction that facilitates both social comparison and mutual support or collective action, it is not surprising that these conceptually distinct theoretical perspectives point to similar social groups-neighbors, friends, co-workers-as the generators of the external effects. While the most relevant co-insurance group for any individual is unlikely to be the whole population of the country of residence, it is reasonable to assume that living in a country with a higher mean income will generally entail greater opportunities for private support when current income is low.

Note that all four reasons can be present at once. For example, a negative effect stemming from relative deprivation can coexist with a positive effect stemming from better public goods in a richer country. For the present purpose, the salient issue for measuring global inequality is whether the net effect is positive or negative.

Evidence from data on self-assessed welfare: Much of the evidence that has been presented in the literature in support of the relative deprivation hypothesis has come from country-level studies using self-reported welfare (typically measured from a survey question on "happiness" or "satisfaction-with-life”) as the dependent variable in a regression with both own income and income for a comparator group as regressors (often along with other controls).

The conclusions drawn from such regressions can be challenged on a number of grounds. The results can depend on the assumed distribution of the error term. ${ }^{18}$ For skewed distributions the results can be sensitive to changing those assumptions, as shown by Bond and Lang (2017). ${ }^{19}$ Another concern in interpreting the evidence from these studies is latent heterogeneity in how respondents interpret the scales used in survey questions; Ravallion et al. (2016) examine this issue for three developing countries using vignettes and find considerable heterogeneity in scales, though regression parameters appear to be reasonably robust.

Putting these concerns to one side, some of the regressions reported in this literature indicate that self-reported happiness or satisfaction with life rises with own-income relative to a

\footnotetext{
${ }^{18}$ Given that the data are ordinal, a nonlinear regression estimator is typically used, such as ordered probit assuming that the error term for the latent continuous variable is normal.

19 This is probably only a serious concern for happiness data that have a highly skewed distribution such as the three-point happiness scale from the General Social Survey. More commonly used scales such as the standard satisfaction with life question used by psychologists appear to be near normally distributed.
} 
comparison group, often defined by co-residents, as in (for example) Luttmer (2005) and Knight et al. (2009). ${ }^{20}$ Using data for the US, Luttmer (2005) cannot reject the null hypothesis that subjective wellbeing is homogenous (of degree zero) in own income and neighborhood income, implying that subjective wellbeing depends on relative income not own-income. Layard et al. (2010) come to a similar conclusion using data for the US, Germany and other countries in Western Europe and Clark et al. (2017) report strong negative effects of comparator income levels (at given own income) on subjective wellbeing in Britain, Germany and Australia. We can call this the strongly relative view, as distinct from the weakly relative view, which assumes that own income still has a positive weight at given relative income (Ravallion and Chen, 2011).

Not all the evidence has found support for the hypothesis of relative deprivation. In testing for such effects in self-reported happiness data from Russia and South Africa (respectively) Senik (2004) and Kingdon and Knight (2007) found evidence of positive external effects of neighbors' income, controlling for own income; the latter paper finds evidence of a negative effect for more distant co-residents of the same country. In a study for Malawi, Ravallion and Lokshin (2010) also found evidence of both positive and negative effects depending on income level, with the positive effect dominant among the poor. They suggest that the informal coinsurance institutions found in rural Malawi can explain this empirical finding.

When considering global inequality, the differences between countries come into playdifferences that obviously cannot be identified in the studies reviewed above using data for a single country. There are some studies using cross-national data, such as Di Tella and MacCulloch (2010), Diener et al. ( 2010) and Diener and Tay (2015). These typically find a positive correlation between mean subjective welfare assessments and national income per capita. ${ }^{21}$ However, these studies cannot tell us whether the effect of higher national income is internal (via own income) or external (at given own income).

There are three papers in the literature that allow one to separate these two effects, and all three point to the existence of (positive) net gains from higher national income at given own income. The first two are by Helliwell (2008) and Helliwell et al. (2010), which are similar enough to be grouped together. These papers estimate regressions for individual (self-reported)

\footnotetext{
${ }^{20}$ Also see the survey by Clark et al. (2008) and the discussion in Ravallion (2014a).

${ }^{21}$ The relationship is also found to be nonlinear, specifically concave, with a marked flattening out at high mean income levels; see, for example, Di Tella and MacCulloch (2010).
} 
subjective wellbeing responses in both the World Values Surveys and the Gallup World Poll, pooling data across countries. The regressors include both own-household income and GDP per capita of the country of residence. In both cases, there is a positive and statistically significant "own-income” effect. The data from the World Values Surveys also indicate a positive and significant effect of national income, at given own income. This is not indicated by the results using the Gallup data set for the sample as a whole, but is found for the OECD sub-sample. Note, however, that the regressions include other national characteristics that are clearly correlated with GDP per capita, such as an index of corruption (with a significant negative effect on subjective welfare) and, in Helliwell et al. (2010), country life expectancy (with a significant positive effect). Thus the total effect of higher national income on subjective wellbeing is undoubtedly higher. Helliwell et al. (2010, p.308) conclude that their global regressions “...suggest that any relative income effects at the national level are being substantially offset by the effects of other excluded variables that support life satisfaction in the richer countries."

The third paper is Diener et al. (2013), also using the micro data from the Gallup World Poll. For the bulk of their analysis the authors averaged the household income variable (and other variables) to national level. However, at one point they briefly compare the effects on reported subjective wellbeing of income differences within nations to those between them. The authors report that there is at best a small effect of relative income within countries but a strong positive effect of the between-nation differences in average income. Diener et al. (2013, p.273) conclude that "... a richer person in a rich nation would be better off than a rich person in a poor country." The authors conjecture that this may be because of better infrastructure in rich countries though there are other possible explanations as discussed above.

In summary: The literature does not leave one very confident about the size or even sign of the personal real-income effect of higher national income at given own income. One finds arguments and empirical support for both negative and positive effects. However, it is notable that the only papers in the literature that tested for an effect of national income on subjective wellbeing using global micro data suggest that the effect is positive. Yet, the only paper on global inequality measurement that allowed for an independent effect of national income assumed that a negative effect, through relative deprivation (Milanovic and Roemer, 2016). So 
the evidence from global subjective welfare studies sits uncomfortably with how global inequality has been measured in the past.

In the light of these observations it is important to know how much prevailing measures of global inequality are affected by allowing national income to matter intrinsically, either positively or negatively. The rest of the paper takes up that issue.

\section{Measuring global inequality when national income matters}

The approach taken here provides a simple way of encompassing the various views on the intrinsic value of national income discussed in the previous section. Household income per capita is scaled up or down by a country-specific multiplicative factor based on the mean. The approach allows for both a non-negative relative-income effect on household welfare and a nonnegative intrinsic effect at given relative income.

Three further points should be noted at the outset. First, the motivation is explicitly welfarist. In response, one might argue that we can be concerned about global inequality based on observed own-incomes whether or not the underlying income or consumption measures from surveys are expected to adequately reflect real income. Against this, the interpretations typically given to inequality measures presuppose the relevance of income to some concept of economic welfare, though possibly the relevant income concept differs from what is available from standard surveys, such as with regard to the time period (as discussed in the previous section). In the following analysis, the received approach is allowed, but only as a special case.

Second, the focus here is on relative inequality, as is almost invariably measured in the literature on global inequality. Relative measures satisfy the usual scale independence axiom, whereby multiplying all incomes by a constant does not change the measure of inequality. Not everyone agrees with this axiom; indeed, surveys of university students suggest that a sizeable minority do not, preferring instead a translation invariance property (whereby adding a constant does not change the measure), which yields absolute inequality measures. ${ }^{22}$

Third, the summary statistic of the distribution of income deemed relevant to individual welfare is taken to be the mean. This accords well with the various motivations from the

\footnotetext{
${ }^{22}$ The first surveys of students to show this were reported in Amiel and Cowell (1999) and it has been confirmed by other surveys since; for further discussion see Ravallion (2014b, 2017a).
} 
literature (Section 2); for example, the mean is likely to be the relevant parameter in determining the resources available for public services not accounted for in own-income. However, relative deprivation arguments have often used the median. In principle, the present approach can be readily modified, replacing the mean with the median, though some properties of the measure do not then go through, as will be noted.

The proposed measure: Let $y_{i j t}>0$ denote the income of household $i$ in country $j$ at time $t$. We can treat $y_{i j t}$ as a continuous random variable, and also presume that its values have been normalized for differences in prevailing prices. Let $m_{j t}$ be the corresponding mean in country $j$ where $m_{t}$ is the global mean with a global population size of $n_{t}$. Global inequality is then measured here for the distribution of real income $y_{i j t}^{*}$ defined by:

$$
\ln y_{i j t}^{*} \equiv \ln y_{i j t}+\alpha \ln \left(m_{j t}\right)
$$

The parameter $\alpha$ reflects the intrinsic value attached to national income, i.e., its weight relative to own-income. (Any instrumental value of a higher mean is taken to already be reflected in $y_{i j t}$.)

The standard approach to measuring global inequality has $\alpha=0$. A range of values for $\alpha$ will be considered, embracing different views on how national income might matter horizontally, between people with the same observed income. A value of $\alpha<-1$ is ruled out by the assumption that $y_{i j t}^{*}$ is non-decreasing in the mean at given relative income. When $\alpha=-1$ we have the strongly relative view of Easterlin (1974) and others whereby only relative income matters $\left(y_{i j t}^{*}=y_{i j t} / m_{j t}\right)$. In considering the upper bound, it will be recalled that the results of past global studies of subjective wellbeing suggest that positive values are more plausible than negative ones. The study by Helliwell et al. (2010) reports regression coefficients of subjective wellbeing on both own-income and national income (GDP per capita), both in logs; the ratio of the coefficient on $\log$ national income to that on $\log$ own-income gives $\alpha$. The regressions suggest a positive value with upper bound estimate around $\alpha=0.5$, though a narrower interval of 0.3-0.5 is suggested for most regression specifications. However, recall that there are also indirect effects of national income through the other control variables used in this study, so the true value is likely to be somewhat higher. For example, the indirect effect via life expectancy alone would probably add about 0.05 to the effect of log national income on satisfaction with 
life, which would raise the upper bound estimate for $\alpha$ to $0.6 .{ }^{23} \mathrm{~A}$ higher value might be defended if one allows for other covariates that are correlated with national income (such as exposure to corruption, as an aspect of institutions, which was also found to be a significant predictor of subjective wellbeing by Helliwell et al.). The following analysis will consider values of $\alpha$ over the interval $[-1,1]$.

While the formulation in (1) generalizes the standard approach to measuring global inequality, it could be generalized further. To give an example, one might prefer to interpret $m_{j t}$ as an unequally-weighted mean, with weights given by how "close" other people are to person $i$ (so that one would need to rewrite the variable as $m_{i j t}$ to allow for idiosyncratic weights). This would allow the idea of (sub-national) “moral comparators.” However, in measuring global inequality, it does not seem an unreasonable simplification to focus on the national (equallyweighted) mean. To give another example, for international migrants one might distinguish the mean income of the country of birth from that of current residence, although the two are the same for $97 \%$ of the world's population (United Nations, 2015), so this is a moot point.

A further extension would relax the restriction that $\alpha$ is a constant. This restriction can be questioned. For example, it might be hypothesized that the negative relative-deprivation effect becomes more important at higher income levels, suggesting a switch in the sign of $\alpha$ (as found for Malawi in Ravallion and Lokshin, 2010). However, given that the present purpose is solely to explore the robustness of prevailing measures of global inequality, it does not seem unreasonable to focus here on the simple one-parameter specification in (1).

In choosing a measure of global inequality, the mean-log deviation (MLD) - given by the log of mean income less the mean of log income-is known to have a number of desirable features. The fact that (unlike the Gini index) MLD is decomposable by population sub-groups is clearly an attractive feature for the present purpose. There are other such decomposable measures including other measures in the class proposed by Theil (1967). However, MLD is the only measure that satisfies both the Pigou-Dalton transfer axiom and the Monotonicity in Distance axiom of Cowell and Flachaire (2017); the former axiom requires that mean-preserving income transfers in which the recipient is poorer (richer) than the donor will decrease (increase)

\footnotetext{
${ }^{23}$ I have used an elasticity of life expectancy to mean income of 0.015 (Pritchett and Summers, 1996), mean life expectancy of 70 years and a regression coefficient of satisfaction with life on log GDP per capita of 0.05 (Helliwell et al., 2010). This calculation is only intended to be broadly indicative.
} 
measured inequality while the Monotonicity in Distance axiom says that, when comparing two distributions that differ in one person's income, the greater the distance from equality, the higher the inequality. Note that MLD is non-negative but not bounded above by unity.

The MLD based on the distribution of $y_{i j t}^{*}$ over all $i, j$ is given by: ${ }^{24}$

$$
L(\alpha)_{t}=\sum_{i} \sum_{j} \ln \left(m_{t}^{*} / y_{i j t}^{*}\right) / n_{t}
$$

where the global mean of the adjusted incomes in (1) is denoted $m_{t}^{*}$. The decomposability of MLD entails that $L(\alpha)_{t}=L^{B}(\alpha)_{t}+L^{W}(\alpha)_{t}$ where

$$
\begin{aligned}
& L^{B}(\alpha)_{t}=\sum_{j} s_{j t} \ln \left(m_{t}^{*} / m_{j t}^{*}\right) \\
& L^{W}(\alpha)_{t}=\sum_{j} s_{j t} L(\alpha)_{j t}
\end{aligned}
$$

are the between and within-country components respectively, and where $m_{j t}^{*}$ is the countryspecific mean of the adjusted incomes, $L(\alpha)_{j t}=\sum_{i} \ln \left(m_{j t}^{*} / y_{i j t}^{*}\right) / n_{j}$ and $s_{j t}=n_{j t} / n_{t}$ is the population share of country $j$. The standard approach in the literature is the special case:

$$
L(0)_{t}=\sum_{i} \sum_{j} \ln \left(m_{t} / y_{i j t}\right) / n_{t}
$$

By contrast, when $\alpha=-1$ global inequality is average inequality across countries (noting that $\left.L^{B}(-1)_{t}=0\right)$. This is "nationalistic" in that inequality between countries receives no weight.

Properties of the measure: Equation (1) entails that all incomes within a given country are multiplied by a constant $\left(m_{j t}^{\alpha}\right)$. So under the scale-independence axiom, the within-country component of global inequality is independent of $\alpha$; all that changes is the between-country component. This does not just involve re-weighting the between- and within-country components of the standard measure. Rather, the between-country component changes. To see this, one can re-write (2) in terms of the ordinary (un-adjusted) incomes, giving:

$$
L(\alpha)_{t}=\ln \left[\sum_{j} s_{j t}\left(m_{j t} / m_{t}\right)^{\alpha+1}\right]+(\alpha+1) L^{B}(0)_{t}+L^{W}(0)_{t}
$$

To better understand the relationship between $L(\alpha)_{t}$ and the usual measure with $\alpha=0$ we need to look more closely at the first term on the right hand side of (5). Consider the limiting case in which $m_{j t}=m_{t}$ for all $j$ whereby $L^{B}(\alpha)_{t}=L^{B}(0)_{t}$. On noting that $m_{j t}^{\alpha+1}$ is convex (concave) for $\alpha>(<) 0$, we have (by Jensen's inequality) that $E\left(m_{j t}^{\alpha+1}\right)>(<)\left(E m_{j t}\right)^{\alpha+1}$ as $\alpha>(<) 0$.

\footnotetext{
${ }^{24}$ Recall that it is assumed that $y_{i j t} \geq 0$. This clearly holds for consumption but need not hold for incomes. For a modification of MLD to allow non-positive values see Ravallion (2017b).
} 
Thus $\sum_{j} s_{j t}\left(m_{j t} / m_{t}\right)^{\alpha+1}>(<) 1$ as as $\alpha>(<) 0$. As long as $m_{j t}$ has positive variance, the term $\ln \left[\sum_{j} s_{j t}\left(m_{j t} / m_{t}\right)^{\alpha+1}\right]$ is positive (negative) for positive (negative) $\alpha$. We see then that negative (positive) weights on national income imply lower (higher) global inequality $\left(L(\alpha)_{t}<\right.$ (>) $L(0)_{t}$ for $\left.\alpha<(>) 0\right)$.

A stronger monotonicity property also holds, namely that $L(\alpha)_{t}$ is a strictly increasing function of $\alpha$ and as long as $m_{j t}$ varies across countries. To verify this, note that, since the within-country component is independent of $\alpha$, we only need look at how the between- country component varies with $\alpha$. Differentiating w.r.t. $\alpha$ we have: ${ }^{25}$

$$
L^{B^{\prime}}(\alpha)_{t}=\sum_{j} s_{j t}\left(\frac{m_{j t}^{*}}{m_{t}^{*}}-1\right) \ln m_{j t}=\frac{\sum_{j}\left(s_{j t} m_{j t}^{\alpha+1} \ln m_{j t}\right)-\left(\sum_{j} s_{j t} m_{j t}^{\alpha+1}\right)\left(\sum_{j} s_{j t} \ln m_{j t}\right)}{\sum_{j} s_{j t} m_{j t}^{\alpha+1}}
$$

On noting that $m_{j t}$ is a random variable with positive variance, the expression on the right-hand side of (6) is the difference between the expected value of the product of the two random variables, $m_{j t}^{\alpha+1}$ and $\ln m_{j t}$, and the product of the expected values of those variables. That difference is positive since the variables have positive covariance (given $\alpha+1>0$ ). Thus we have verified that $L^{B^{\prime}}(\alpha)_{t}>0$ and (hence) that $L(\alpha)_{t}$ is also an increasing function of $\alpha{ }^{26}$

We will now see what all this looks like empirically.

\section{New measures of global inequality}

The sources of the household survey data are the World Bank's PovcalNet, the Luxembourg Income Study (LIS) and the European Union Statistics on Income and Living Conditions (EU-SILC). ${ }^{27}$ I have used data for 144 countries, being all those with two surveys. ${ }^{28}$ Both surveys for a given country use the same indicator, either current household consumption or income per person. Given a degree of predictable income variability over time, consumption is used in preference to income when there is a choice; consumption is used for about two-thirds of countries, while disposable income is used for the rest; the latter is more common in Latin America and the OECD. Current-year population weights are used, as provided in PovcalNet.

\footnotetext{
${ }^{25}$ Note that $m_{j t}^{*}=m_{j t}^{\alpha+1}$.

${ }^{26}$ If one prefers to use the median rather than the mean then monotonicity is no longer assured. (This was pointed out to me by Emmanuel Flachaire in correspondence.)

27 The specific data set used here is described more fully in Ravallion and Chen (2017).

${ }^{28}$ This is not essential, but avoids concerns about non-random attrition when the set of countries changes over time.
} 
Following standard practice, the country-specific consumer price indices are used to convert to a common base year, in this case 2011, and survey means in local currency units are converted to \$s at 2011 purchasing power parity (PPP) using the consumption PPPs from the International Comparison Program. PPPs deal with the fact that many goods and services are not globally traded so their prices vary, depending (in particular) on local wage rates.

The median year for the first survey is 1993 and it is 2012 for the second. Figure 1 gives the kernel densities of $\ln \left(m_{t} / m_{j t}\right)$ around these two dates. The decline in inequality between countries is evident; the between-country component of MLD as conventionally measured is the (population-weighted) mean of the densities in Figure 1 which falls from 1.03 to 0.76. Figure 2 provides the corresponding densities of the national MLDs. We see the expected shift to the right (higher inequality within countries) across most of the range of MLD. There is an exception, however, for high-inequality countries (MLD over 0.6) for which there are fewer cases around 2012. This could be corrections to initial measurement errors, although prior research has also suggested there is a process of inequality convergence across countries when one allows for classical measurement errors in the estimation method (Ravallion, 2003). There is only a small positive correlation ( $r=0.191 ; n=144)$ between the annualized changes in MLD between the earliest and latest surveys and the annualized growth rates in the mean, and it is not statistically significant. ${ }^{29}$ Thus these estimates conform to one of the stylized facts identified by Ferreira and Ravallion (2009) that growth in the mean tends to be distribution-neutral on average.

Table 1 gives $L(\alpha)_{t}$ for various values of $\alpha$ while Figure 3 plots $L^{B}(\alpha)_{t}$ against $\alpha$. (Recall that the within-country component does not vary with $\alpha$.) For the standard case of $\alpha=0$ we see a decrease in the MLD based on observed consumptions or incomes, driven by the fall in the between-country component. As expected given monotonicity (section 3), negative values of $\alpha$ yield a lower between-country component, bringing down the overall inequality index (Table 1). The opposite holds for positive values (implying that people in richer countries are better off at given own-consumption). This is all in line with the theoretical expectation.

We see that the quantitative magnitudes are sizeable. By construction, going from $\alpha=0$ to $\alpha=-1$ brings the global measure down to average inequality within countries — a large (63-

\footnotetext{
29 The t-test on the regression coefficient of the annualized change in log MLD on the annualized change in log mean gives $\mathrm{t}=1.27$ (prob. $=0.20$ ) using a heteroscedasticity-consistent standard error.
} 
76\%) reduction (Table 1). If proportionate increases in national consumption matter about as much as those for own consumption (an $\alpha=1$ type person) then the global inequality measure is more than doubled, with the between-country component rising to about $90 \%$ of the total.

Three observations help put the numbers in perspective. First, note that the differences in MLD over the range of $\alpha$ greatly exceed the range in levels of inequality found across countries using the standard approach. This is evident on comparing Table 1 with Figure 2; the MLDs across countries for the earliest (latest) years range from 0.07 (0.10) to 1.13 (0.96). Going from $\alpha=-1$ to $\alpha=1$ increases the inequality measure 14 of the standard deviations of the crossnational distribution of MLD for the earliest surveys, and 12 standard deviations for the latest. Across the range of $\alpha$, the implied differences in MLD swamp the cross-country differences in MLD for $\alpha=0$. If we focus on $\alpha=0.6$ then the global MLD for the more recent surveys is up to twice the global value at $\alpha=0$, and over $50 \%$ higher than the highest value for any country.

Second, even with $\alpha$ in $[-0.2,0.2]$ (say), the global inequality index (for 1990) changes by an amount that is greater than the absolute change observed over this 20 year period. Differences over the value of $\alpha$ also swamp the differences over time at given $\alpha$.

The third observation relates to the concern in the recent literature on the implications for measured inequality of a systematic under-estimation of the incomes of the rich in household surveys. ${ }^{30}$ The differences in measures of inequality according to $\alpha$ are comparable to, or even larger than, those implied by even a seemingly large underestimation of the incomes of the rich. Suppose, for example that incomes of all the richest $1 \%$ in the world are actually double the numbers in Lakner and Milanovic (2016) for 2008. ${ }^{31}$ This would add about 0.1 to MLD. ${ }^{32}$

As expected, a higher weight on national income implies higher global inequality. As is evident from Figure 3, I also find that the claim that the between-country component of global inequality has fallen over this period is robust to the choice of $\alpha$. Given that the within-country component of $L(0)_{t}$ has risen over time, it turns out that the qualitative conclusion that overall global inequality fell over the period is only robust for $\alpha>-0.7$ (Table 1 ).

\footnotetext{
${ }^{30}$ For example, Korinek et al. (2006) estimate that correcting for selective compliance in household surveys would add around 0.05 to the Gini index for the U.S. Similarly, on using income tax records to supplement survey data one finds higher inequality measures; see, for example, Piketty and Saez (2003).

${ }^{31}$ Lakner and Milanovic estimate that in 2008 the world's richest $1 \%$ had an average income of $\$ 64,213$ (converted at PPP for 2005) while the overall mean was $\$ 4,097$.

${ }^{32}$ Let all incomes of the richest $p^{r}$ proportion of the population, with income share $s^{r}$, be underestimated by a factor $k$. Then the change in MLD is $\left(s^{r}-p^{r}\right) \ln k$.
} 


\section{Conclusions}

It is surely remarkable that measures of global inequality attribute no economic advantage to living in a richer country beyond what is already reflected in the household incomes measured from surveys. The assumption that the advantages, or possibly disadvantages, of living in a richer country are fully reflected in the survey-based incomes is hard to defend on either theoretical or empirical grounds. The paper finds that some prominent stylized facts about global inequality are not robust to attaching an intrinsic value to higher national income.

Competing theories have been considered here. The idea of relative deprivation postulates negative externalities from economic gains to co-residents. So too does a neoclassical growth model when it is recognized that "own-income" is almost certainly measured in surveys over a shorter period of time than people evaluate their expected future welfare. The nationalistic view that "global inequality" is just the average national inequality across countries emerges as the limiting case in which it is relative income within the country of residence that matters.

By contrast, one can point to plausible theoretical arguments for positive external effects of living in a richer country at given own income. Examples of the transmission mechanisms include the likely positive correlation between national income and factors conducive to a higher long-run personal income, greater opportunities for leisure, better public services, better regulations and better social protection. None of these gains are likely to be properly reflected in current incomes as measured in surveys. And there is evidence to support all these mechanisms. The implication is clear: the (large) differences in average incomes found between rich and poor countries create an extra (horizontal) inequality between their residents, not reflected in their observed current incomes. This is a downward bias in prevailing measures of global inequality.

The paper's results suggest that this bias is highly salient to the quantitative measures obtained of global inequality from standard data sources. A person who defines her economic welfare in terms of relative income alone will see far less inequality in the world than a person who puts a sizeable value on the external benefits of living in a richer country. Using what can be considered the ideal inequality measure for this purpose, the paper finds that relative deprivation theory implies that global interpersonal inequality is far lower than prevailing measures suggest since it is then entirely within countries. However, this changes dramatically when one allows a positive intrinsic value of national income, such as when living in a richer 
country brings benefits in terms of access to non-market goods and services, and better opportunities for private support in times of need.

It is hard to be confident as yet on the magnitude of the intrinsic value of higher national income, and the topic merits further research. From what we know now based on past global studies of subjective well-being, it is possible that the national income effect is $50 \%$ or more of the own-income effect. Then global inequality is far higher than prevailing measures suggest, and far higher than found in even the most unequal country. Indeed, the differences in levels of inequality due to even rather modest differences in how one values national mean income tend to swamp the differences seen over time in standard measures, or the differences we see between countries, and are also large relative to the impact on global inequality of even a substantial underestimation of the incomes of the rich.

The stylized fact that global inequality has been falling since around 1990 is not robust, though one only finds rising inequality with a seemingly high negative weight on national income, such as due to relative deprivation. The finding of falling between-country inequality is robust whatever intrinsic value (positive or negative) one attaches to national income in assessing individual economic welfare. 
Table 1: Global inequality measures

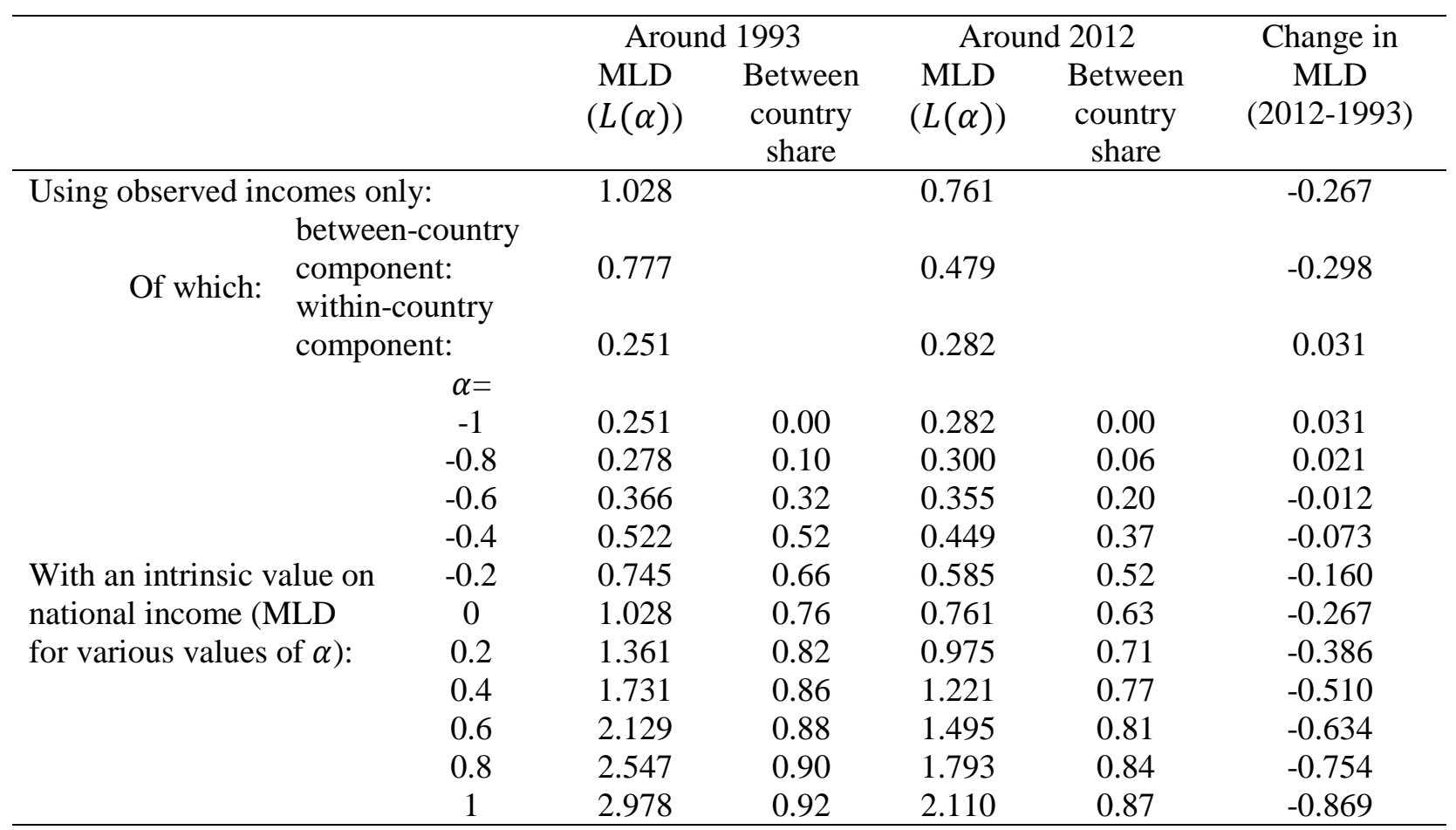

Sources: Author's calculations (see text). 
Figure 1: Densities of $\ln \left(m_{t} / m_{j t}\right)$

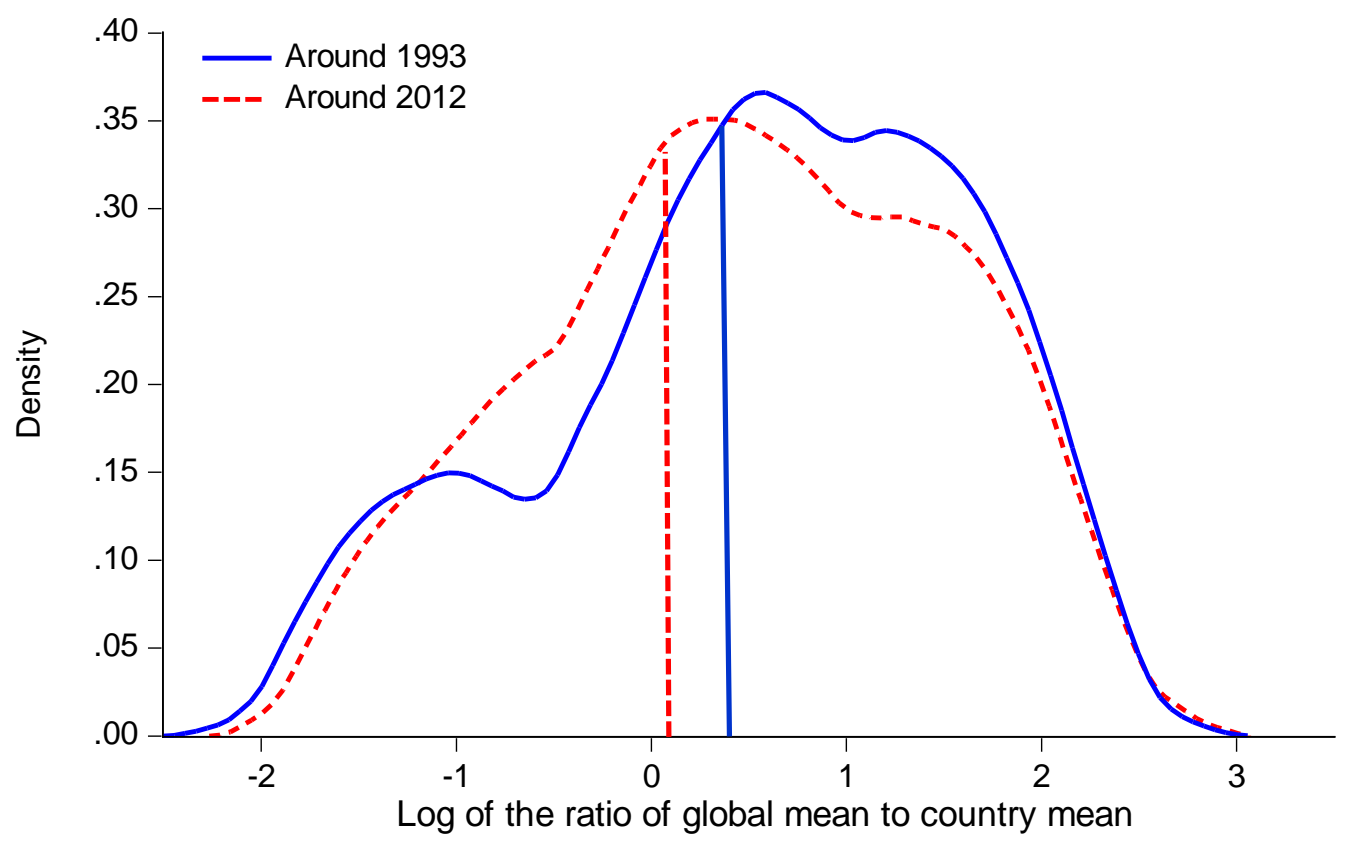

Figure 2: Densities of MLD across countries

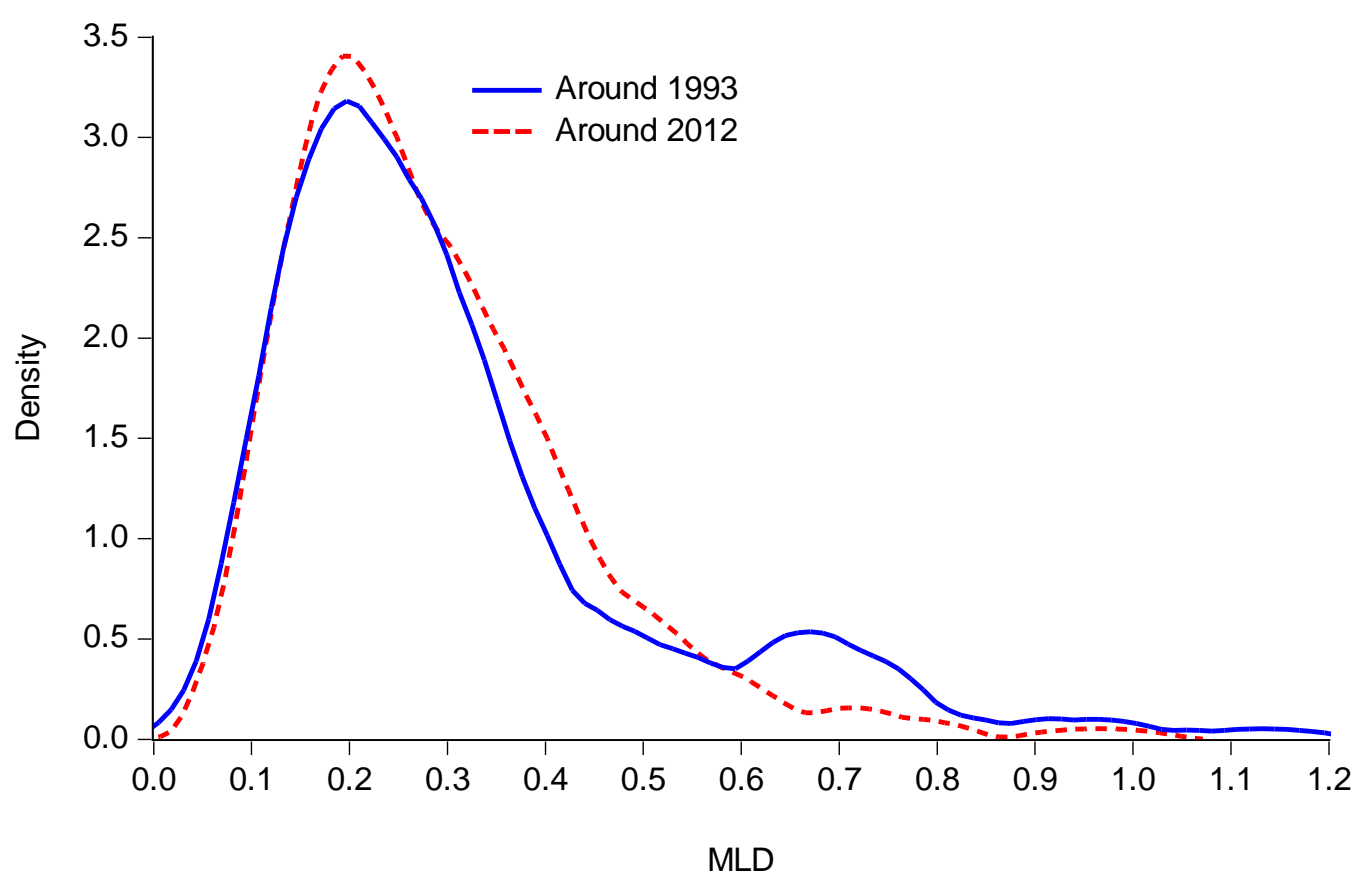


Figure 3: Between-country component of global inequality

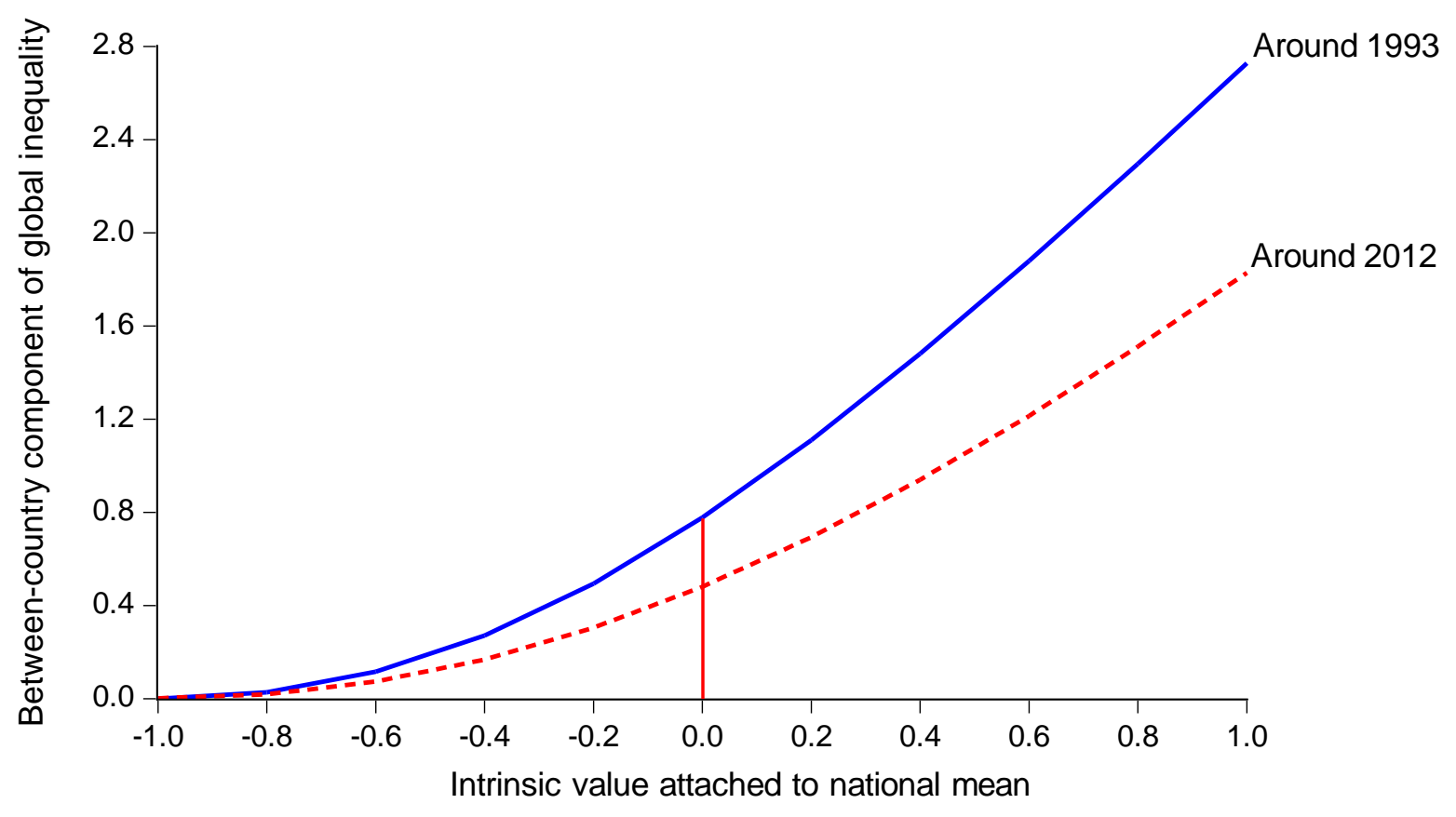




\section{References}

Afonso, António, and José Alves, 2017, “Reconsidering Wagner’s law: Evidence from the Functions of the Government,” Applied Economics Letters 24(5): 346-350.

Akitoby, Bernardin, Benedict Clements, Sanjeev Gupta and Gabriela Inchauste, 2006, "Public Spending, Voracity, and Wagner's Law in Developing Countries," European Journal of Political Economy 22(4): 908-924.

Amiel, Yoram, and Frank Cowell, 1999, Thinking about Inequality: Personal Judgment and Income Distributions. Cambridge, Mass.: Cambridge University Press.

Barro, Robert, and Xavier Sala-i-Martin, 1995, Economic Growth, New York: McGraw Hill.

Beck, Ulrich, 2006, Cosmopolitan Vision. Cambridge: Polity Press.

Bhattacharya, Aveek, 2015, “Global Inequality is Falling. So What?” Carnegie Council for Ethics in International Affairs.

Bick, Alexander, Nicola Fuchs-Schundeln and David Lagakos, 2017, "How do Hours Worked Vary with Income? Cross-Country Evidence and Implications,” American Economic Review, forthcoming.

Bond, Timothy and Kevin Lang, 2017, “The Sad Truth About Happiness Scales,” mimeo, Boston University.

Bourguignon, Francois, 2016, The Globalization of Inequality, Princeton: Princeton University Press.

Bourguignon, Francois and Christian Morrisson, 2002, "Inequality among World Citizens: 18201992,” American Economic Review 92(4): 727-744.

Brandolini Andrea, and Francesca Carta, 2016, "Some Reflections on the Social Welfare Basis of the Measurement of Global Income Inequality,” Journal of Globalization and Development 7(1): 1-15.

Buchanan, Allen, 2000, “Rawls’s Law of Peoples: Rules for a Vanished Westphalian World," Ethics 110(4): 697-721.

Caney, Simon, 2005, Justice Beyond Borders. A Global Political Theory. Oxford: Oxford University Press.

Charness, Gary, and Garance Genicot, 2009, “Informal Risk Sharing in an Infinite-horizon Experiment,” Economic Journal 119(537): 796-825. 
Clark, Andrew, Paul Frijters, and Michael Shields, 2008, "Relative Income, Happiness and Utility: An Explanation for the Easterlin Paradox and Other Puzzles,” Journal of Economic Literature 46(1): 95-144.

Clark, Andrew, Sarah Fleche, Richard Layard, Nattavudh Powdthavee and George Ward, 2017, "The Key Determinants of Happiness and Misery," in John Helliwell, Richard Layard and Jeffrey Sachs (eds) World Happiness Report 2017, New York: United Nations.

Clemens, Michael, Claudio Montenegro and Lant Pritchett, 2008, “The Place Premium: Wage Differences for Identical Workers Across the US Border,” Policy Research Working Paper No. 4671, World Bank.

Coate, Stephen, and Martin Ravallion, 1993, "Reciprocity Without Commitment: Characterization and Performance of Informal Insurance Arrangements,” Journal of Development Economics 40: 1-25.

Cowell, Frank, and Emmanuel Flachaire, 2017, "Inequality Measures and the Median: Why Inequality Increased more than we Thought,” mimeo, London School of Economics.

Cowen, Tyler, 2014, “Income Inequality Is Not Rising Globally. It's Falling.” New York Times. July 19.

Davis, James, 1959, “A Formal Interpretation of the Theory of Relative Deprivation,” Sociometry 22: 280-296.

Diener, Ed, W. Ng, J. Harter and R. Arora, 2010, “Wealth and Happiness across the World: Material Prosperity Predicts Life Evaluation, whereas Psychosocial Prosperity Predicts Positive Feeling," Journal of Personality and Social Psychology 99(1): 52-61.

Diener, Ed, Louis Tay and Shigehiro Oishi, 2013, "Rising Income and the Subjective Well-being of Nations,” Journal of Personality and Social Psychology 104(2): 267-276.

Diener, Ed, and Louis Tay, 2015, "Subjective Well-being and Human Welfare around the World as Reflected in the Gallup World Poll,” International Journal of Psychology 50(2): 135149.

Di Tella, Rafael, and Robert MacCulloch, 2010, "Happiness Adaptation to Income Beyond Basic Needs,” in Ed Diener, John Helliwell and Daniel Kahneman (eds) International Differences in Well-Being, Oxford: Oxford University Press. 
Duesenberry, James S., 1949, Income, Saving and the Theory of Consumer Behavior, Cambridge, Mass.: Harvard University Press.

Easterlin, Richard A., 1974, “Does Economic Growth Improve the Human Lot? Some Empirical Evidence,” in P.A. David and W.R. Melvin (eds) Nations and Households in Economic Growth, Palo Alto: Stanford University Press.

Economist, The, 2014, “Let them Eat Cosmopolitanism,” The Economist Magazine, July 21. Ferreira, Francisco, and Martin Ravallion, 2009, "Poverty and Inequality: The Global Context,” in Wiemer Salverda, Brian Nolan and Tim Smeeding (eds) The Oxford Handbook of Economic Inequality, , Oxford: Oxford University Press.

Frank, Robert H., 1985, Choosing the Right Pond: Human Behavior and the Quest for Status. New York: Oxford University Press.

Helliwell, John, 2008, “Life Satisfaction and Quality of Development,” NBER Working Paper 14507.

Helliwell, John, Chris Barrington-Leigh, Anthony Harris and Haifang Huang, 2010, “International Evidence on the Social Context of Well-Being,” in Ed Diener, John Helliwell and Daniel Kahneman (eds) International Differences in Well-Being, Oxford: Oxford University Press.

Kanbur, Ravi, 2006, “The Policy Significance of Inequality Decompositions,” Journal of Economic Inequality 4: 367-374.

Kingdon, Geeta, and John Knight, 2007, “Community, Comparisons and Subjective Well-being in a Divided Society,” Journal of Economic Behavior and Organization 64(1): 64-90.

Knight, John, Lina Song, Ramani Gunatilaka, 2009, “Subjective Well-Being and Its Determinants in Rural China,” China Economic Review 20(4): 635-49.

Korinek, Anton, Johan Mistiaen and Martin Ravallion, 2006, "Survey Nonresponse and the Distribution of Income,” Journal of Economic Inequality 4(2): 33-55.

Lakner, Christoph, and Branko Milanovic, 2016, “Global Income Distribution: From the Fall of the Berlin Wall to the Great Recession,” World Bank Economic Review 30(2): 203-232.

Layard, Richard, G. Mayraz, and S. Nickell, 2010, “Does Relative Income Matter? Are the Critics Right?” in Ed Diener, John Helliwell and Daniel Kahneman (eds) International Differences in Well-Being, Oxford: Oxford University Press. 
Ligon, E., Thomas, J., Worrall, T., 2002, “Informal Insurance Arrangements with Limited Commitment: Theory and Evidence from Village Economies,” Review of Economic Studies 69, 209-244.

Lucas, Robert, 1988, “'On the Mechanics of Economic Development,” Journal of Monetary Economics 22(1): 3-42.

Luttmer, Erzo, 2005, “Neighbors as Negatives: Relative Earnings and Well-being,” Quarterly Journal of Economics 120: 963-1002.

McKenzie, David, Steven Stillman, and John Gibson, 2010, “How Important is Selection? Experimental vs. Non-experimental Measures of the Income Gains from Migration,” Journal of the European Economic Association 8(4): 913-945.

Milanovic, Branko, 2005, Worlds Apart: Measuring International and Global Inequality, Princeton University Press. , 2015, “Global Inequality of Opportunity: How Much of our Income is Determined by Where we Live?,” Review of Economics and Statistics 97(2): 452-460. 2016, Global Inequality: A New Approach for the Age of Globalization.

Cambridge, Mass: Harvard University Press.

Milanovic, Branko, and John E. Roemer, 2016, “Interaction of Global and National Income Inequalities,” Journal of Globalization and Development 7(1): 109-115.

Musgrave, Richard, 1969, Fiscal Systems, Yale University Press, New Haven.

Nagel, Thomas, 2005, “The Problem of Global Justice,” Philosophy and Public Affairs 33(2): 113-147.

O’Neill, Martin, 2008, “What Should Egalitarians Believe?” Philosophy and Public Affairs 36(2): 120-156.

Peacock, Alan, and Alex Scott, 2000, “The Curious Attraction of Wagner's Law,” Public Choice 102(1-2): 1-17.

Piketty, Thomas, and Emmanuel Saez, 2003, “Income Inequality in the United States, 19131998,” Quarterly Journal of Economics 18(1): 1-41.

Pritchett, Lant, and Lawrence H. Summers, 1996, “Wealthier is Healthier” Journal of Human Resources 31(4): 841-868

Ravallion, Martin, 2003, “Inequality Convergence,” Economics Letters 80: 351-356. 
, 2008, "On the Welfarist Rationale for Relative Poverty Lines," in Kaushik

Basu and Ravi Kanbur (eds) Social Welfare, Moral Philosophy and Development: Essays in Honour of Amartya Sen's Seventy Fifth Birthday, Oxford: Oxford University Press. , 2012, “Why Don’t we See Poverty Convergence?” American Economic Review, 102(1): 504-523. , 2014a, "Poor or Just Feeling Poor? On Using Subjective Data in Measuring Poverty.” In Andrew Clark and Claudia Senik (eds), Happiness and Economic Growth, Oxford: Oxford University Press. , 2014b, "Income Inequality in the Developing World," Science 344: 851-5. , 2016, The Economics of Poverty: History, Measurement and Policy. New

York: Oxford University Press. , 2017a, "Inequality and Globalization: A Review Essay,” Journal of Economic Literature, forthcoming. , 2017b, “A Concave Log-Like Transformation Allowing Non-Positive Values,” Economics Letters, 161: 130-132.

Ravallion, Martin, Kristen Himelein and Kathleen Beegle, 2016, “Can Subjective Questions on Economic Welfare be Trusted?” Economic Development and Cultural Change 64(4): 697-726.

Ravallion, Martin, and Shaohua Chen, 2011, "Weakly Relative Poverty,” Review of Economics and Statistics 93(4): 1251-1261. , and , 2017, "Welfare-Consistent Global Poverty Measures When Relative Incomes Matter,” NBER Working Paper 23739.

Ravallion, Martin, and Michael Lokshin, 2010, "Who Cares About Relative Deprivation?” Journal of Economic Behavior and Organization. 73(2): 171-185.

Rawls, John, 1999, The Law of Peoples, Cambridge MA: Harvard University Press. Rayo, Luis, and Gary S. Becker, 2007, “Evolutionary Efficiency and Happiness,” Journal of Political Economy 115(2): 302-337.

Rodrik, Dani, 2017, “Is Global Equality the Enemy of National Equality?” CEPR Discussion Paper No. DP11812. 
Runciman, W.G., 1966, Relative Deprivation and Social Justice, London: Routledge and Kegan Paul.

Senik, Claudia, 2004, "When Information Dominates Comparison: Learning from Russian Subjective Panel Data,” Journal of Public Economics 88: 2099-2123.

Singer, Peter, 2010, The Life You Can Save: How to do your Part to End World Poverty, New York: Random House.

Theil, Henri, 1967, Economics and Information Theory, Amsterdam: North-Holland.

United Nations, 2015, Trends in International Migrant Stock: The 2015 Revision. United Nations Department of Economic and Social Affairs, Population Division.

Walster, Elaine, William Walster, and Ellen Berscheid, 1978, Equity: Theory and Research. Boston: Allyn and Bacon. 